Research Article

\title{
Research on the Definition of Economic Limits for the Development of Unconventional Natural Gas under New Situations
}

\author{
Zuxin Li $\mathbb{D}^{1,},{ }^{1,2}$ Jianye Liu $\mathbb{D}^{1},{ }^{1}$ Dongkun Luo ${ }^{D},{ }^{1}$ Xiuling Yin, ${ }^{2}$ and Dufen Sun ${ }^{2}$ \\ ${ }^{1}$ School of Business Administration, China University of Petroleum-Beijing, Beijing 102249, China \\ ${ }^{2}$ Department of Overseas New Ventures Assessment, Research Institute of Petroleum Exploration \& Development, \\ Beijing 100083, China \\ Correspondence should be addressed to Zuxin Li; leezx-69@hotmail.com, Jianye Liu; jianyeliu2015@163.com, and Dongkun Luo; \\ lizx609@163.com
}

Received 9 January 2020; Revised 9 April 2020; Accepted 10 April 2020; Published 29 April 2020

Academic Editor: Sergio Ortobelli

Copyright ( $\odot 2020$ Zuxin Li et al. This is an open access article distributed under the Creative Commons Attribution License, which permits unrestricted use, distribution, and reproduction in any medium, provided the original work is properly cited.

\begin{abstract}
The development of unconventional natural gas in China is facing three new situations: market-oriented pricing reform, intensified competition in state subsidies, and reduced production capacity growth, which may cause the development of unconventional natural gas to be on the edge of economic feasibility. Therefore, the definition of economic limit is even more important. In this paper, through analysis on the historical prices, outputs, and subsidy policies of three unconventional natural gases, methods to estimate future prices, subsidies, and outputs of unconventional natural gas are designed in this paper based on the mean reversion model and the generalized Weng model, respectively; fuzzy data are processed by using probability density function combined with a discounted cashflow method to improve the utilization of original data; the economic limit model for well depth, well spacing, and gas recovery rate is designed through break-even analysis with the subsection function of drilling cost to well depth, the modified Cher Card Geoff empirical formula of recovery ratio to well spacing, as well as the fitting formula of gas recovery rate and stable production time. This model is applied in the case of Deep CBM Block Ji 4\&10. According to the estimation and case calculation, in future China, the subsidies for unconventional natural gas will gradually decrease and the gas output will significantly increase, with shale gas taking the leading position and CBM gradually declining; the economic limits of well depth, well spacing, and gas recovery rate of Ji $4 \& 10$ are 2,203.2 m, $300 \mathrm{~m} \times 300 \mathrm{~m}$ and $469 \mathrm{~m} \times 469 \mathrm{~m}$, and $2.1 \%$ and $4.3 \%$, respectively, under the economic infeasibility probability of $90 \%$, and the overall economic infeasibility probability is $58 \%$, indicating that the development of this block is subject to great risks and careful consideration needs to be given.
\end{abstract}

\section{Introduction}

Thanks to the gas shortage in winter caused by the strong increase in demand and insufficient supply of natural gas, the development of unconventional natural gas in China has been rapidly increasing in recent years under the substantial subsidies from the central government. However, the development of China's unconventional natural gas industry is facing new situations, posing new challenges to the development and utilization of oil and gas. There are mainly three new situations as follows:

(1) The market-oriented pricing reform of natural gas has been vigorously promoted: on November 4, 2019, the
National Development and Reform Commission (amended document on Catalogue of Pricing by the Central Government) stipulated that prices of shale gas and CBM stations should be formed according to the market, and tight gas should be temporarily managed according to the current pricing mechanism and may be formed according to the market depending on the market-oriented reform process of natural gas in due time. Pursuant to this regulation, the sales prices of unconventional natural gas in China will no longer be determined by the state, but by the market. (2) Subsidy policies for unconventional natural gas has changed greatly: in China, subsidies for shale gas and CBM development used to be independent of each other, 
with the fixed subsidy $\left(\mathrm{RMB} 0.3 / \mathrm{m}^{3}\right)$; while according to the new subsidy policy issued on June 19, 2019 (Supplementary Notice on the Interim Measures for the Administration of Special Funds for the Development of Renewable Energy), the total amount of subsidy for unconventional natural gas is fixed, and competition and reward and punishment policies are implemented, rewarding those exceeding the recovery quantity of the previous year and deducting the amount of subsidy for those failing to exceed the same. (3) The growth rate of the output of unconventional natural gas is slowing down: although China's unconventional natural gas is still developing rapidly, the growth rate is decreasing. Since 2016, the annual output of the CBM industry has been kept at 7 billion $\mathrm{m}^{3}$, with no new growth [1]. The annual output of tight gas increased by $126.7 \%$ (from 15 to 34 billion $\mathrm{m}^{3} /$ year) from 2009 to 2013, while in the last 5 years (2014 to 2018 ), it increased only by $27 \%$ (from 37 to 47 billion $\mathrm{m}^{3} /$ year); shale gas exploitation started late, with the commercial gas flow formed in 2013. The annual output increased by about 3 billion $\mathrm{m}^{3}$ before 2015 while only by about 1.5 billion $\mathrm{m}^{3}$ after 2015 (Source: Historical news reports, annual reports and statistical yearbooks of the National Bureau of Statistics and the National Development and Reform Commission). This shows that in China, the growth rate of unconventional natural gas is slowing down. In the past, under the stimulation of policies, easyto-develop blocks have been developed rapidly under the intervention of the state, while the remaining blocks are difficult to develop, causing the slow growth of production today.

China's unconventional natural gas development is facing three new situations, namely, pricing reform, subsidy competition, and capacity changes. The economic evaluation of previously developed blocks is relatively simple with the definition of economic limits being unimportant because of good resource situation and basically fixed gas prices and subsidies. However, under the new situations, gas prices are determined by the market, subsidies are determined by competition, and the resource situations of the blocks are worse. Therefore, the development of unconventional natural gas may be on the edge of economic feasibility. Therefore, it is highly necessary to analyze and study methods for defining economic limits to assist design optimization and investment decisions and to prevent mistakes in the deployment of the plans.

\section{Overview and Limitations of Design Methods for Development Parameters}

\subsection{Overview of Methods for Defining Economic Limits of} Development Parameters. For development design, there are feasible fields for subjective parameters, such as well depth, well spacing, and gas recovery rate. The boundaries for the economic feasible range are economic limits, the boundary for the technical feasible range is technical limit, and the subset of the both is just the design feasible region for the final development. The definition of economic limits is to define the economically feasible boundaries of parameters like well depth, well spacing, and gas recovery rate.

For well density design, the general approach [2] is to design several possible well spacings for the development, estimate the gas output with such methods as numerical simulation, calculate economic benefits according to the estimated output, and select the best well density according to the comparative benefits. The research mainly focuses on the impact mechanism of well density on the final output, for instance, the impact of different well densities on the recovery ratio [3]; although some researchers, considering the time value of funds [4], have chosen the discounted cashflow method to calculate the economic limits of well density, they failed to consider such realistic situations as changes in the prices and subsidies in the future.

The design of drilling depth is less subjective than that of well density because the depth of the gas-bearing layer is often determined objectively, and the research on depth limits is generally in engineering and technical perspectives, such as drilling methods [5], reservoir forming conditions [6], changes in reservoir conditions [7], and brittle ductility [8]. As for the economic limits, some scholars [9] have studied the calculation methods of critical depth based on break-even analysis. However, at the initial stage for the design of the development plan, the original data are fuzzy or difficult to obtain, and the practicability of accurate calculation methods is still open to question.

For gas recovery rate, some studies [10] have analyzed the impact of different gas recovery rates on formation pressure and hydrodynamic conditions from the microscopic level, and some studies $[11,12]$ have focused on the impact of unreasonable gas recovery rate on permeability. A few scholars [13] have studied the relationship between gas recovery rate and stable production period of gas reservoirs, but failed to further calculate the economic benefits.

2.2. Analysis on the Limitations of Existing Methods under the New Situations. According to the literature review in Section 2.1, previous research on feasible fields of development parameters was generally based on engineering and technical perspectives, and the feasibility of design parameters was rarely considered from an economic perspective; a few economy-related researches failed to take into account the actual development situations, such as data acquisition, accuracy issues, and changes in gas prices and policies. In the past, when gas prices and policy subsidies were relatively high, insufficient attention was paid to the methodological research on economic feasibility. Therefore, it may not adapt to future conditions under the new situations.

The new market and policy situations have put forward new requirements for methods of economic limits, which are mainly reflected in the following aspects: (1) marketbased pricing will lead to the increase or decrease in the sales prices of unconventional natural gas in some areas, which may affect the economic feasibility of development blocks. Therefore, it is necessary to predict and estimate 
future prices and calculate economically feasible well densities and drilling depths. (2) The competitive subsidy mechanism will cause the strong to be awarded and the weak to be punished. The higher the gas output, the higher the reward, which will further affect the gas output curve and gas yield in the blocks under development. Therefore, it is necessary to predict the future subsidy amounts and select economically feasible gas recovery rates. (3) The realistic situation that the gas recovery rate decreases shows that the difficulty of increasing the output is further increased and the risk tolerance is reduced. Therefore, higher requirements have been put forward for the calculation accuracy of economic limits. However, there is no accurate original data at the initial stage for the design of the development plan, so the calculation method is subject to higher requirements.

In summary, it is necessary to analyze and predict the sales prices and subsidies of unconventional natural gas in China in the future on the basis of existing research data and to design a new economic limits model targeting the original fuzzy data based on the time value and break-even balance to make maximum use of the existing data and improve the calculation accuracy.

\section{Methods for Predicting and Estimating Economic Parameters}

Under the new situations, the sales price directed and the fixed subsidies set up by the state in the past no longer exist, forcing us to estimate the future trend of economic parameters such as gas prices and subsidies as the basis for studying economic limits.

\subsection{Prediction of Future Prices of Unconventional Natural Gas.} For unconventional natural gas, the prices used to be subject to the unified guidance of the government, with little difference in prices of stations in different provinces. However, under the new situations, the prices will be set by the market, so the historical prices of the stations will no longer be representative. China's unconventional natural gas is distributed at different geographical locations and has different supply markets, so it is necessary to estimate the future prices of three unconventional natural gases, respectively. Shale gas and CBM are mainly supplied to local markets, such as Baode CBM Block in Shanxi and Fuling CBM Block in Chongqing. Tight gas, however, is supplied to the national market through the national pipeline network, for example, gas from Sulige Gas Field is mainly supplied to the North China market. Therefore, after market-oriented pricing, the future prices of the three unconventional natural gases will definitely be different.

As for shale gas, China's shale gas is mainly produced in Chongqing and Sichuan. In 2018, Fuling in Chongqing produced 6.02 billion $\mathrm{m}^{3}$ of shale gas, and the shale gas output of PetroChina in Sichuan was 4.27 billion $\mathrm{m}^{3}$. Therefore, the producer price indexes of oil and natural gas exploration industries (O\&G PPI) in Chongqing City and Sichuan Province were selected as the price indexes of shale gas weighted according to this proportion. For CBM, in 2018, Shanxi produced 5.135 billion $\mathrm{m}^{3}$ of CBM, accounting for $70.7 \%$ of the national output. Therefore, the O\&G PPI in Shanxi Province were selected as the price index of CBM. Tight gas is supplied to the national market. Therefore, the PPIs of the national oil and natural gas exploration industries were selected as the price indexes of tight gas. The specific data are shown in Table 1.

Obviously, from the perspective of mean, there have been no much changes in the PPIs of the three gases in the past 10 years. However, the fluctuation over the years has been very high. Therefore, the simple mean alone cannot be regarded as the future price trend of unconventional natural gases in China. According to some researches $[14,15]$, oil price fluctuation is a geometric Brownian motion. In this paper, the fluctuation of China's unconventional oil and gas prices is also regarded as a geometric Brownian motion, which has the same characteristic of mean reversion as oil prices [15]. Without considering emergencies, the basic model of mean reversion is shown in the following formula:

$$
\mathrm{d} \ln P_{t}=k\left(\mu-\ln P_{t}\right) \mathrm{d} t+\sigma \mathrm{d} z_{t},
$$

where $P_{t}$ is the gas price, $\mu$ is the mean of the logarithm of the gas price, $k$ is the mean reversion speed, $\sigma$ is the volatility of the logarithm of the price, which reflects the random volatility of the price, and $z_{t}$ is the standard Brownian motion, $\mathrm{d} z_{t} \sim(0, \mathrm{dt})$, reflecting the uncertainty of price change. Using the mean reversion model to fit the price indexes of the three unconventional natural gases mentioned above, the results are shown in the following formula:

$$
\left\{\begin{array}{l}
\mathrm{d} \ln P_{\text {СвM }}=0.726\left(4.615-\ln P_{\text {СBM }}\right) \mathrm{d} t+0.049 \mathrm{~d} z_{t}, \\
\mathrm{~d} \ln P_{\text {Shale Gas }}=0.773\left(4.599-\ln P_{\text {ShaleGas }}\right) \mathrm{d} t+0.044 \mathrm{~d} z_{t}, \\
\mathrm{~d} \ln P_{\text {Tight Gas }}=0.925\left(4.569-\ln P_{\text {TightGas }}\right) \mathrm{d} t+0.250 \mathrm{~d} z_{t} .
\end{array}\right.
$$

In formula (2), $P_{\mathrm{CBM}}, P_{\text {ShaleGas, }}$ and $P_{\text {TightGas }}$ are the price indexes of three unconventional natural gases, respectively.

3.2. Prediction of Future Subsidies for Unconventional Natural Gases. China's subsidy policies for unconventional gases used to focus on CBM and shale gas. From 2007 onwards, the central treasury subsidized mining enterprises at the standard of RMB $0.2 / \mathrm{m}^{3}$ for CBM, which continued until 2016, after which the subsidy standard rose to RMB $0.3 / \mathrm{m}^{3}$ until November 2019. The subsidy standard for shale gas was $\mathrm{RMB} \quad 0.4 / \mathrm{m}^{3}$ during $2012-2015$ and $\mathrm{RMB} \quad 0.3 / \mathrm{m}^{3}$ during 2016-2019. Tight gas has not been subsidized as it is seldom considered as an unconventional natural gas in China. China's new natural gas policy has introduced competition mechanism and reward and punishment mechanism, with the calculation in the following formulas and formula (5): 
TABLE 1: PPIs of oil and natural gas exploitation industries in supply markets of three unconventional natural gases in recent 10 years (last year $=100)$ (The oil and natural gas producer price indexes (O\&GPPI) come from Chongqing Statistical Yearbook, Sichuan Statistical Yearbook, Shanxi Statistical Yearbook, and China Statistical Yearbook in recent 10 years; the PPI of China in 2018 only includes data of the first 9 months. The PPI data by province is not available, so it is calculated according to the national PPI changes by proportion).

\begin{tabular}{|c|c|c|c|c|c|c|c|c|c|c|c|c|}
\hline Category & Market & 2009 & 2010 & 2011 & 2012 & 2013 & 2014 & 2015 & 2016 & 2017 & 2018 & Mean \\
\hline $\mathrm{CBM}$ & Shanxi & 100.7 & 100.3 & 106.5 & 100.3 & 100.9 & 103.8 & 99.4 & 90.7 & 110.3 & 98.5 & 101.14 \\
\hline Shale gas & Sichuan and Chongqing & 99.96 & 104.94 & 104.63 & 100.08 & 101.41 & 100.89 & 94.77 & 89.53 & 100.19 & 98.6 & 99.5 \\
\hline Tight gas & China & 66 & 137.8 & 124.5 & 99.6 & 96.5 & 96.6 & 62.7 & 83.6 & 129 & 98.2 & 99.45 \\
\hline
\end{tabular}

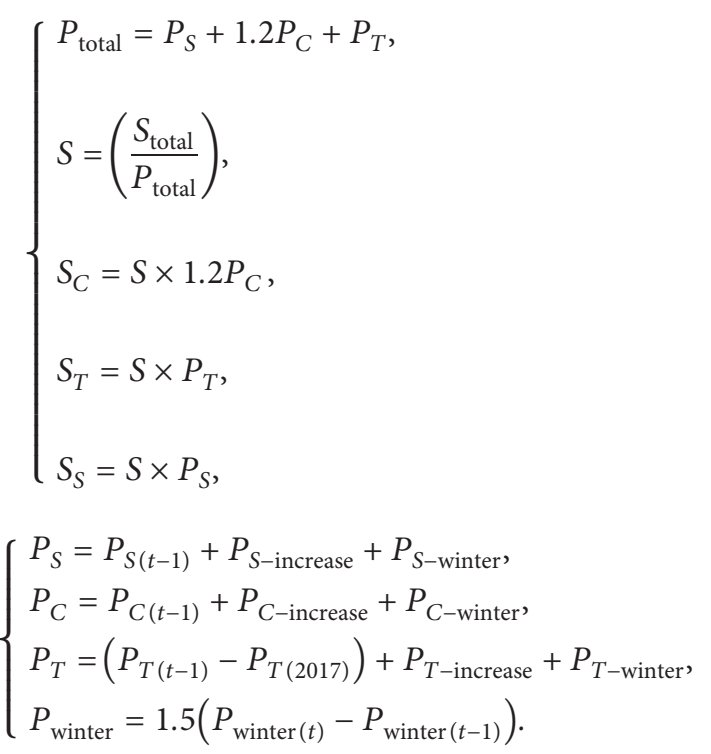

In formula (3), $P_{\text {total }}$ is the subsidized amount for unconventional natural gas in the country, with $P_{S}, P_{C}$, and $P_{T}$ being the subsidized amounts for shale gas, CBM, and tight gas, respectively; $S_{\text {total }}$ is the total amount of subsidies for unconventional natural gas allocated by the central government in the year, $S$ is the amount of subsidy for each cubic meter of unconventional natural gas, and $S_{S}, S_{C}$, and $S_{T}$ are the total amounts of subsidy for shale gas, CBM, and tight gas in the year, respectively.

In formula (4), $P_{S(t-1)}, P_{C(t-1)}$, and $P_{T(t-)}$ are the outputs of the three unconventional natural gases in the previous year, respectively. $P_{S-\text { increase }}, P_{C-\text { increase }}$, and $P_{T-\text { increase }}$ are the amounts of rewards and punishments for the annual growth, respectively. $P_{S \text {-winter }} P_{C \text {-winter }}$, and $P_{T \text {-winter }}$ are the rewards and punishments for increased output in winter this year. $P_{\text {winter }(t)}$ is the output of a certain unconventional natural gas in winter (January-April) of the year, and $P_{\text {winter }}(t-1)$ is the output in the previous winter (January-April); $\mathrm{P}_{T(2017)}$ is the output of tight gas in 2017; let $\sigma=(p(t)-p(t-1)) / p(t-1)$, for the reward and punishment amounts $P_{\text {increase }}$ for the growth of certain unconventional natural gas in this year; the calculation should follow formula (3) as shown in the following formula:

$$
P_{\text {increase }}=\left\{\begin{array}{l}
1.25\left(P_{(t)}-P_{(t-1)}\right) ; \quad|\delta| \leq 5 \%, \\
1.50\left(P_{(t)}-1.05 P_{(t-1)}\right)+1.25 \times 5 \%\left(P_{(t-1)}\right) ; \quad 5 \%<|\delta| \leq 10 \%, \\
1.75\left(P_{(t)}-1.10 P_{(t-1)}\right)+1.25 \times 5 \%+1.50 \times 5 \%\left(P_{(t-1)}\right) ; \quad 10 \%<|\delta| \leq 20 \%, \\
2.00\left(P_{(t)}-1.20 P_{(t-1)}\right)+1.25 \times 5 \%+1.50 \times 5 \%+1.75 \times 10 \%\left(P_{(t-1)}\right) 20 \%<|\delta| .
\end{array}\right.
$$

In formula (5), $P_{(t)}$ is the output of a certain unconventional natural gas in that year and $P_{(t-1)}$ is the output in the previous year.

Similarly, the output data of three unconventional natural gases in China in the past 10 years are selected to predict the future output so as to calculate the subsidies. The specific data are shown in Table 2.

It is considered that the output of unconventional natural gases is not only related to subsidies but also related to the sales prices and the time of exploitation. As for the relationship between oil and gas outputs and time, many practitioners of the petroleum industry have established classic models, such as the Hubbert model and the generalized Weng model [16, 17]; although they are mainly used in single oil fields, such models have also been used by many scholars for predicting the oil and gas production regions $[18,19]$, and the generalized Weng model is used to describe the changes in the output with time, as shown in the following formula:

$$
Q_{t}=a t^{b} e^{-(t / c)}
$$

It is considered that the impact of subsidy and price on output is linear, and the following improved model is obtained as shown in the following formula:

$$
Q_{t}=a t^{b} e^{-(t / c)}+k_{1} p+k_{2} S+d
$$

In formula (7), $a, b, c, d, K_{1}$, and $K_{2}$ are the model parameters, $Q$ is the output, $P$ is the price, and $S$ is the subsidy amount.

The rapid development of China's tight gas, CBM, and shale gas started in 2006, 2008, and 2012, respectively. The subsidy amount, output, and price indexes in the past 10 years are introduced into formula (6). After calculation, the 
TABLE 2: Outputs of three nnconventional natural gases in recent 10 years (unit: 100 million $\mathrm{m}^{3}$ ) (The data is collected by the author according to courses as historical reports of the National Energy Administration and the National Bureau of Statistics as well as annual reports of the companies. Since the tight gas outputs in 2017 and 2018 are highly disputable, the means are adopted).

\begin{tabular}{lcccccccccc}
\hline Year & 2009 & 2010 & 2011 & 2012 & 2013 & 2014 & 2015 & 2016 & 2017 & 2018 \\
\hline CBM & 7 & 14 & 23 & 27 & 30 & 35.4 & 44 & 74.8 & 70.2 & 72.6 \\
Shale gas & - & - & - & - & 2 & 13 & 44.7 & 78.8 & 91 & 108.81 \\
Tight gas & 150 & 160 & 256 & 320 & 340 & 370 & 400 & 421 & 446 & 470 \\
\hline
\end{tabular}

fitting relationship among the subsidy, price, and output of the three unconventional natural gases is shown in the following formula:

$$
\left\{\begin{array}{l}
Q_{C-t}=4.039 \times(t-2007)^{1.5} \times e^{-((t-2007) / 8.590)}+0.5127 \times P_{c-t}+305.85 \times S_{c-(t-1)}-114.43, \\
Q_{S-t}=0.836 \times(t-2011)^{3.1} \times e^{-((t-2011) / 9.580)}+0.2305 \times P_{s-t}+304.38 \times S_{S-(t-1)}-149.00, \\
Q_{T-t}=16.116 \times(t-2005)^{2.0} \times e^{-((t-2005) / 6.943)}+0.6999 \times P_{T-(t-1)}-62.27 .
\end{array}\right.
$$

In formula (8), $Q_{c-t}, Q_{S-t}$, and $Q_{T-t}$ are the outputs of CBM, shale gas, and tight gas of China in Year $t$, respectively; $P_{c-t}$ and $P_{S-t}$ are the prices of CBM and shale gas in Year $t$, respectively, and $P_{T-(t-1)}$ is the price of tight gas of China in Year $t-1 ; S_{c-(t-1)}$ and $S_{S-(t-1)}$ are subsidies for CBM and shale gas in Year $t-1$, respectively.

Without considering emergencies, assuming that the total subsidy amount $S_{\text {total }}$ in the future will remain unchanged and that the sensitivity of tight gas to the subsidy amount is at the average level of shale gas and CBM, the prediction of future subsidies can be obtained by combining formulas (8) and (3)-(5).

\section{Economic Limit Model Based on Probability Density Functions}

In the study of economic limits, some scholars [4, 9] studied the use of the discounted cashflow method and break-even analysis to define the economic limits of design parameters, but they failed to consider the fuzziness of the original data. The purpose for defining economic limits of design parameters is to determine and optimize the development plan. However, before the development plan is designed and optimized, some geological parameters, such as reserves, depth, gas content, and gas-bearing area are not accurate, which will restrict the accuracy of calculation.

\subsection{Discounted Cashflow Model Based on Probability Density.} The fuzziness of the original data exists objectively. For example, before the parameter design of the development plan, the resource reserves will be represented by three levels, P10, 50, and P90. Obviously, taking the most probable value or the mean will distort the original data. In order to make the best use of the original data, this paper intends to design a basic economic evaluation model based on probability density functions and the discounted cashflow method.

The discounted cashflow method is a basic method widely used in economic evaluation of oil and gas industries.
It takes into account the time value of funds, and its basic formula is as shown in the following formula:

$$
\mathrm{NPV}=\sum_{t=1}^{n}(\mathrm{CI}-\mathrm{CO})_{t}(1+i)^{-t} \text {. }
$$

In formula (9), NPV is the net present value; $\mathrm{CI}$ is the cash inflow, including subsidies and sales revenue; $\mathrm{CO}$ is the cash outflow, including various investments and costs; and $i$ is the discount rate.

Considering the basic process of unconventional natural gas exploration and development in China, the exploration investment is regarded as the sunk cost before the development plan is designed, and therefore, formula (9) can be further expanded and written as follows:

$$
\begin{aligned}
\mathrm{NPV}= & \sum_{t=1}^{n}\left(R_{\mathrm{sal}-t}+R_{\mathrm{sub}-t}-I_{\mathrm{dev}-t}-I_{\mathrm{con}-t}-C_{\mathrm{opex}-t}-T_{\mathrm{tax}-t}\right) \\
& \times(1+i)^{-t} .
\end{aligned}
$$

In formula (10), $R_{\text {sal }-t}, R_{\text {sub- } t}, I_{\text {dev }-t}, I_{\text {con- } t}, C_{\text {opex }-t}$, and $T_{\operatorname{tax}-t}$ are, respectively, the sales revenue, subsidy income, development investment (drill and completion and fracturing), construction investment (surface facilities and well pattern), operation cost, and taxes of unconventional oil and gas development in Year $t$.

Formula (10) is applicable to economic evaluation based on accurate original data, but the original data before the design of development parameters are fuzzy, so the discounted cashflow model will use the fuzzy data. For the development and design of unconventional natural gas, the distribution form of the original data directly affects the calculation results. Therefore, it is required to define the distribution types of original data, which are usually as shown in Table 3.

In Table 3, the distribution types of reserves come from researches in the field of petroleum engineering [20,21]. The price distribution has been analyzed as mentioned above. 
TABLe 3: Distribution types of development parameters of unconventional natural gas.

\begin{tabular}{lccc}
\hline Original data & Distribution type & Data format & Range \\
\hline Reserve & Logarithmic normal distribution & $(\mathrm{P} 10, \mathrm{P} 50, \mathrm{P} 90)$ & $>0$ \\
Sales price & Mean jump reversion & $\mathrm{d} \ln P_{t}=k\left(\mu-\ln P_{t}\right) \mathrm{d} t+\sigma \mathrm{d} z_{t}$ & $\mathrm{X} \sim \mathrm{N}(\mu, \sigma 2)$ \\
Depth & Normal distribution & $\mathrm{X} \sim \mathrm{N}(\mu, \sigma 2)$ & $>0$ \\
Quality & Normal distribution & $($ min, mean, mean, max $)$ & - \\
Stable production time & Trapezoid-like distribution & $(\min , \operatorname{mean}, \max )$ & $(0,1]$ \\
Gas recovery rate & Triangular distribution & $(\min , \operatorname{mean}, \max )$ & $(0,1)$ \\
Lapse rate & Triangular distribution & \\
\hline
\end{tabular}

The subsidies are calculated according to existing policies and depending on competition in output, so the distribution types are not determined. The remaining distribution types come from the results of discussion of the author with relevant experts.

It is obvious that the probability distribution of the parameters in Table 3 will affect the cash inflow and outflow in formula (10). For example, price will affect the sales revenue, subsidy will affect the subsidy income, and depth will affect the drilling cost in the development investment. Therefore, according to the break-even method of Xia and Luo [9], when NPV $=0$, the values of the parameters will be the economic limit boundaries. The impact of well depth, well spacing, and gas recovery rate on cashflow will be analyzed, respectively, to establish an economic limit model.

4.2. The Critical Well Drilling Depth Mode. For unconventional natural gas in China, drilling depth will directly affect drilling cost. Therefore, it is necessary to clarify the relationship between drilling cost and well depth. It should be noted that although fracturing cost is affected to some extent, the depth will not be significantly increased. The drilling cost is related to the type of rig used, while the choice of drilling is related to geological conditions and depth [22]. It is considered that the unit footage cost of drilling increases rapidly with the increase of depth. The greater the depth, the higher the unit footage cost. The estimation follows the following formula:

$$
C_{z s}=f(d)=\left\{\begin{array}{l}
d \times \lambda_{1}, \\
\left(d-k_{1}\right) \times \lambda_{2}+k_{1} \times \lambda_{1}, \\
\left(d-k_{1}-k_{2}\right) \times \lambda_{3}+k_{2} \times \lambda_{2}+k_{1} \times \lambda_{1}, \\
\ldots \ldots
\end{array}\right.
$$

In formula (11), $\mathrm{d}$ is the drilling depth, $C_{\mathrm{zs}}$ is the drilling cost, $\lambda_{1}<\lambda_{2}<\lambda_{3}$ are the unit footage costs of different depths, and $k_{1}$ and $k_{2}$ are the critical depths of different rigs.

When NPV $=0$, the well depth is at the economic limit, and formula (12) can be obtained by combining formulas (10) and (11):

$$
d_{\max }=f^{-1}\left\{\sum_{t=1}^{n}\left[R_{\mathrm{sal}-t}+R_{\mathrm{sub}-t}-\left(I_{\mathrm{dev}-t}-C_{z s}\right)-I_{\text {con }-t}-C_{\mathrm{opex}-t}-T_{\mathrm{tax}-t}\right] \times(1+i)^{-t}\right\} .
$$

In formula (12), $f^{-1}$ is the inverse of $f(d)$ and $d_{\max }$ is the economic limit of drilling depth when the designed drilling depth exceeds this limit value.

4.3. The Critical Well Spacing Density Mode. Well spacing, on the one hand, affects the number of wells, thus affecting the corresponding development investment and, on the other hand, affects gas output, thus affecting sales revenue. Insufficient well spacing will cause too dense wells, resulting in the inability to recover the drilling development investment; excessive well spacing will cause reduced utilization rate of resources, making it impossible to recover the investment in pipeline network construction and surface construction.

Well spacing affects both output and development investment. Its impact on the development investment is relatively simple. Let the well spacing be akm $\times$ bkm, and the development investment can be obtained by the following formula:

$$
I_{\mathrm{dev}}=\frac{S}{a \times b} \times i_{\mathrm{dev}}
$$

In formula (13), $S$ is the area of the block under development, $a \times b$ is the control area of a single well, then $(S / a \times b)$ is the number of wells under development, and $i_{\mathrm{dev}}$ is the average development investment of a single well.

In terms of output, Cher Card Geoff (В.Н. шелкачев) of the former Soviet Union fitted the empirical function of well density and recovery ratio. Relevant scholars [23, 24] have applied it to oilfields; Xie [25] introduced this formula to the field of CBM, considering that the relationship between well density and recovery ratio of CBM to be as shown in the following formula:

$$
R_{r}=R \times e^{-z(a \times b)} .
$$

In formula (14), $R_{r}$ is the recovery ratio; $R$ is the final desorption degree; and $z$ is the gas reservoir coefficient, which depends on geological and resource conditions [26]. 
This paper holds that the well density and well spacing of shale gas and tight gas are similar and that formula (13) can be further applied to the field of unconventional natural gas.
Therefore, formula (10) can be further rewritten into the following formula:

$$
\mathrm{NPV}=\sum_{t=1}^{n}\left[Q \times R \times e^{-z(a \times b)} \times\left(r_{\text {sal }-t}+r_{\text {sub }-t}\right)-\frac{S}{a \times b} \times i_{\text {dev }}-I_{\text {con }-t}-C_{\text {opex }-t}-T_{\text {tax }-t}\right] \times(1+i)^{-t}
$$

In formula (15), $Q$ is the resource reserve and $r_{\text {sal }-t}$ and $r_{\text {sub }-t}$ are the sales price and subsidy amount of each cubic meter of natural gas in the Year $t$, respectively.

Similarly, for formula (15), when NPV $=0$, the value of well density $a \times b$ is the economic limit boundary. Different from well depth, which has only the maximum boundary, well density has not only the maximum boundary but also the minimum boundary.

4.4. The Critical Gas Recovery Rate Mode. For the gas recovery rate, if the change of maintenance cost caused by the increase in well plugging risk due to the change in gas recovery rate is not considered, the gas recovery rate only affects the final output. Too slow gas recovery rate will lead to too long recovery cycle and high time cost of capital, while too fast gas recovery rate will lead to unstable pressure of gas reservoir, which may easily cause well plugging. Some scholars [13] have studied the relationship between gas recovery rate and stable production period of gas reservoirs and believed that the relationship between gas recovery rate $q_{D}$ and recovery rate $R_{\mathrm{r}}$ of constant volume gas reservoirs is as shown in the following formula:

$$
q_{D}=\alpha \times\left(1-R_{r}\right)^{2}+\beta .
$$

In formula (16), $q_{D}$ is the gas recovery rate during stable production period and $\alpha$ and $\beta$ are fitting coefficients, which are determined by gas reservoir characteristics.

Substituting formula (16) in (10), an economic limit model of gas recovery rate can be obtained, as shown in the following formula:

$$
\mathrm{NPV}=\sum_{t=1}^{n}\left[Q \times\left(1-\sqrt{\frac{q_{D}-\beta}{\alpha}}\right) \times\left(r_{\text {sal }-t}+r_{\text {sub }-t}\right)-I_{\text {dev }}-I_{\text {con }-t}-C_{\text {opex }-t}-T_{\text {tax }-t}\right] \times(1+i)^{-t} .
$$

Similarly, when NPV $=0$, the economic limit boundary of gas recovery rate can be obtained with formula (16). It should be noted that formula (16) does not specify the estimation of investment costs and taxes, which are both related to the production profile. The total production duration $n$ also has a quantitative relationship with the gas recovery rate $q_{D}$, so the boundary of the gas recovery rate also has a maximum value and a minimum value.

4.5. Profile of Other Parameter Estimation Methods. In the three economic limit models of formulas (12)-(16), four cashflows are included, namely, development investment $I_{\mathrm{dev}-t}$, construction investment $I_{\text {con- } t}$, operating cost $C_{\text {opex }-t}$, and $\operatorname{tax} T_{\operatorname{tax}-t}$. Here, the estimation methods are briefly described.

The estimation formula for development investment $I_{\mathrm{dev}-t}$ is shown in the following formula:

$$
\begin{gathered}
I_{\mathrm{dev}}=C_{z s}+C_{f}, \\
C_{f}=N_{f} \times c_{f} .
\end{gathered}
$$

In formula (18), the estimation method of drilling cost $C_{\mathrm{zs}}$ is shown in formula (11), with $C_{f}$ being the fracturing cost, $N_{f}$ being the fracturing layer number, and $c_{f}$ being the average fracturing cost per layer.
The estimation formula for construction investment $I_{\text {con- } t}$ is shown in the following formula:

$$
I_{\text {con }}=I_{\text {fac }}+I_{\text {pip }}=Q \times q_{D} \times i_{\text {fac }}+\frac{S}{a \times b} \times i_{\text {pip }} .
$$

In formula (19), $I_{\mathrm{fac}}$ is the construction investment of the surface treatment plant, which is related to the annual treatment capacity. The higher the annual gas output during the stable production period, the higher the plant construction investment. $i_{\text {fac }}$ is the average surface plant investment for treatment of each cubic meter of natural gas. $I_{\text {pip }}$ is the construction investment of surface pipeline network facilities, which is related to the number of wells. The more wells, the higher the investment in well pattern construction. $i_{\text {pip }}$ is the average investment of surface pipeline network per well.

The estimation formula for operation costs $C_{\mathrm{opex}-t}$ follows the following formula:

$$
C_{\text {opex }}=\frac{S}{a \times b} \times c_{\text {opex }-a}+C_{\text {opex }-b} .
$$

In formula (20), the operating costs mainly include workers' wages, management costs, vehicle fuel power, and marketing costs. Most of them are related to the number of wells, such as workers' wages, fuel power costs, and maintenance costs. $C_{\text {opex }-a}$ is the increased operating cost for each additional well. A few items of operating costs are basically 
unrelated to the number of wells, such as marketing expenses and management expenses, which are recorded as $C_{\text {opex }-b}$.

The estimation formula for $\operatorname{tax} T_{\operatorname{tax}-t}$ follows the following formula:

$$
\begin{aligned}
T_{\mathrm{tax}}= & R_{\mathrm{sal}} \times\left(r_{1}+r_{2}\right)+R_{\mathrm{sub}} \times r_{1} \times\left(r_{3}+r_{4}\right) \\
& +\left(R_{\mathrm{sal}}+R_{\mathrm{sub}}-C_{\mathrm{opex}}-D_{\mathrm{ep}}\right) \times r_{5} .
\end{aligned}
$$

In formula (21), where $D_{\text {ep }}$ is the depreciation and amortization; $r_{1}, r_{2}, r_{3}, r_{4}$, and $r_{5}$ are value-added tax, resource tax, construction tax, education surcharge, and business income tax rates, which are $10 \%, 4.2 \%, 7 \%, 3 \%$, and $15 \%$, respectively.

\section{Model Application}

In the model in Section 4, the estimation formulas of various parameters are complicated; especially under the new situations, our input parameters will also be probability density functions instead of specific values, which increases the complexity of the operation. Therefore, we need to give an example to briefly explain the application of the abovementioned model.

5.1. Profile of the Block in Discussion. For the economic limit model, there is no typical particularity among CBM, shale gas, and tight gas, so it is not necessary to illustrate the application of the model to each unconventional natural gas. In view of the fact that deep CBM is often on the edge of economic feasibility, Ji 4\&10, a deep CBM block in Jixian County, is chosen as the research object in order to highlight the significance of economic limit. Ji $4 \& 10$ is one of the few deep CBM blocks to be developed in China, with a coal seam depth of $1200-1400 \mathrm{~m}$ and a reserve abundance of about $0.7-1.3 \times 10^{8} \mathrm{~m}^{3} / \mathrm{km}^{2}$. It is a CBM block with unsatisfactory resource parameters. Therefore, it is urgent to define its economic limit boundaries in order to support the design of the development plan. The basic conditions of this block are shown in Table 4 [27].

Other parameters then can be estimated are as follows: the gas-bearing area to be developed is $16.4 \mathrm{~km}^{2} ; \lambda_{1}, \lambda_{2}$, and $\lambda_{3}$ are unit footage costs of different critical depths $k_{1}$ and $k_{2}$ (formula (11)), $k_{1}$ being $220 \mathrm{~m}$ and $k_{2}$ being $1,187.9 \mathrm{~m} ; \lambda_{1}$ is $\operatorname{RMB} 742 / \mathrm{m}, \lambda_{2}$ is RMB $1,294 / \mathrm{m}$, and $\lambda_{3}$ is RMB $1,678 / \mathrm{m}$. The average number of fracturing layers $N_{\mathrm{f}}$ is 2.4 ; the surface plant investment for treatment of each cubic meter of natural gas on average $i_{\text {fac }}$ is RMB $1 / \mathrm{m}^{3}$. The construction investment of surface pipeline network facilities per well $I_{\text {pip }}$ is RMB $1.72 \times 10^{5} /$ well. In the operating costs, the cost related to the number of wells $c_{\text {opex }-a}$ is RMB $2.05 \times 10^{5} /$ well/ year, and the unrelated part $C_{\text {opex }-b}$ is RMB $3.4 \times 10^{5} /$ year. The tax is calculated according to formula (21), with a discount rate of $10 \%$. The final resolution $R$ is $82 \%$, the parameters $\alpha$ and $\beta$ are $8.897 \%$ and $2.352 \%$, respectively.

5.2. Calculation of Economic Parameters. For the block in discussion, we need not only the exploration and development parameters mentioned above but also the economic parameters of the block under development. The most important thing is the estimation of prices and subsidies. According to the estimation methods in Sections 3.1 and 3.2, we have made relevant calculation on Block Ji $4 \& 10$ and the results are as follows: Block Ji $4 \& 10$ is located in Jixian County, Shanxi Province, so the prediction results of formula (2) can be directly used to draw the diagram of price probability density as shown in Figure 1; according to formulas (3)-(8), the basic subsidy amount for China's unconventional natural gas in the future can be calculated iteratively, and the calculation results are shown in Figure 2.

5.3. Calculation Results of Various Economic Limits. According to the exploration and development parameters and economic parameters of the block, in combination with the economic limit calculation model mentioned above, we can calculate the economic feasibility and economic limits of Block Ji $4 \& 10$. The four calculation results mentioned below are corresponding to the four models in Sections 4.1-4.4, respectively.

5.3.1. Economic Evaluation Results. According to formulas (10) and (18)-(21) and Table 4, we can evaluate the economic feasibility of Block Ji $4 \& 10$. The data used in the model are mostly for probability distribution, so the calculation process will be described briefly.

First, the probability distribution of the gas output curve in Block Ji $4 \& 10$ can be calculated according to the distribution of parameters like resource abundance, gas-bearing area, recovery ratio, stable production time, and lapse rate in Table 4, as shown in Figure 3. The present value of singlewell sales income in the future can be calculated by multiplying Figure 3 (gas output curve) with the sales price (Figure 1) in combination with formula (9), as shown in Figure 4 . The present value of total expenditure for a single well in the future can be calculated by combining Figure 3 (gas output curve), investment cost, and tax parameters with formulas (18)-(21), as shown in Figure 5. The final development benefits of Block Ji $4 \& 10$ can be obtained by subtracting future expenditures from sales revenue and in combination with the prediction of subsidies as shown in Figure 2 and formulas (3), (4), and (10), as shown in Figure 6.

It can be seen from Figure 6 that with subsidies considered, the probability for the final development benefits of Block Ji $4 \& 10$ to be less than 0 is about $58 \%$, indicating economic infeasibility; the probability for the same to be greater than 0 is $42 \%$, revealing economic feasibility. This result is calculated based on the probabilistic discount cashflow model and will be used as the basis for the calculation of the following three economic limits.

5.3.2. Calculation Results of Well Depth Limit. It is obvious that in Figure 6, we take the well depth distribution as an input parameter, as shown in Table 4 , and the input range is $\mathrm{X} \sim \mathrm{N}(1,300,1,350)$. In the well depth limit model, the buried depth will be taken as a variable specific value. According to 
TABLE 4: Distribution of some parameters in the development plan of Block Ji $4 \& 10$.

\begin{tabular}{lcc}
\hline Original data & Distribution & Unit \\
\hline Abundance & $\mathrm{X} \sim \mathrm{N}(1.0,0.4)$ & $10^{8} \mathrm{~m}^{3} / \mathrm{km}^{2}$ \\
Depth & $\mathrm{X} \sim \mathrm{N}(1300,1350)$ & $\mathrm{m}$ \\
Quality & The sulfur content in this block is very low and negligible. & - \\
Stable production time & $(5.2,6.7,9.5,11.1)$ & Year \\
Gas recovery rate & $(3.1 \%, 3.7 \%, 4.3 \%)$ & - \\
Lapse rate & $(5 \%, 8.12 \%, 11 \%)$ & - \\
Fracturing cost & $(30,45,55)$ & $\mathrm{RMB} 10^{4} / \mathrm{layer}$ \\
Well density & $(6.25,8.16,11.11)$ & $\mathrm{Well}^{2} / \mathrm{km}^{2}$ \\
\hline
\end{tabular}

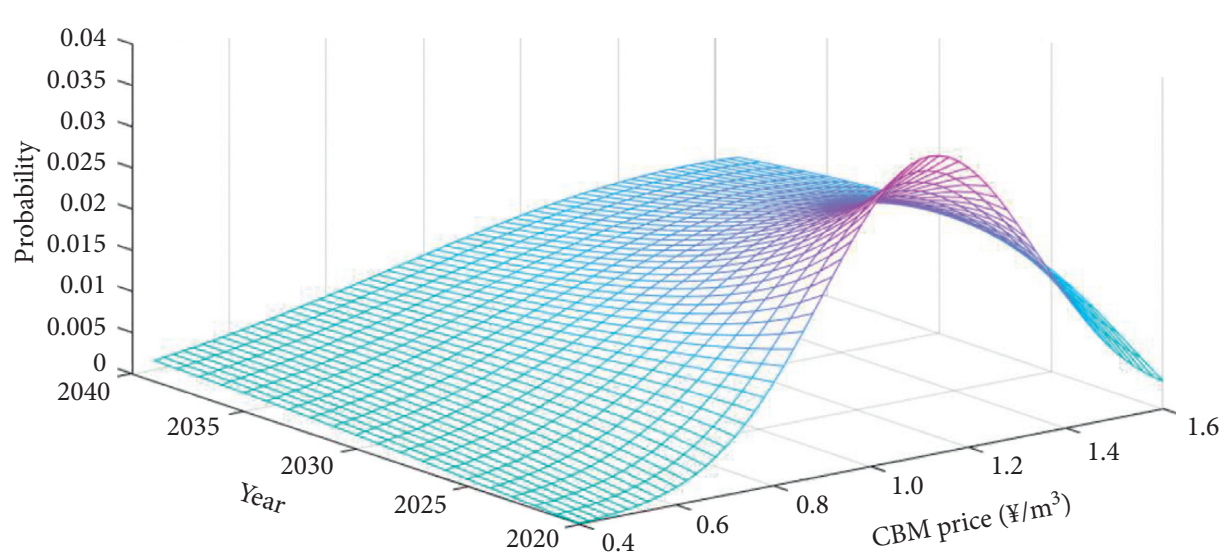

FIGURE 1: Probability density for predicting future sales price of Deep CBM in Block Ji 4\&10.

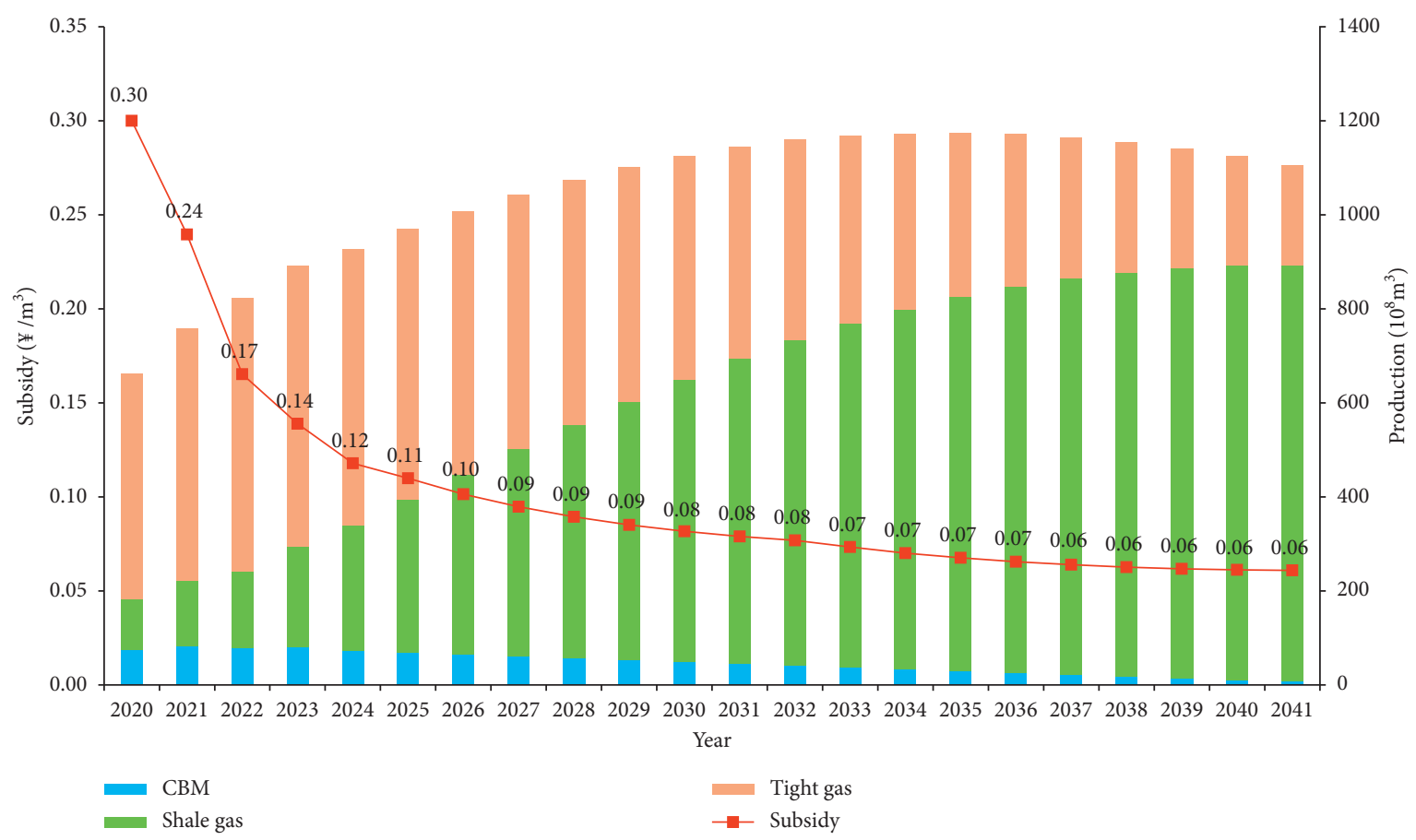

FIgUre 2: Prediction of future output and basic subsidy amounts of unconventional natural gas in China.

formulas (10)-(12), the probability of NPV $=0$ at different well depths is obtained. Taking $1,200 \mathrm{~m}$ as an example, it is calculated that the drilling cost at this depth is RMB 1.4359 million. The probability distribution of NPV with such drilling investment is shown in Figure 7, with the probability of economical infeasibility at about $51.8 \%$. The probability of NPV $<0$ at different depths is calculated, respectively, and the calculation results are shown in Table 5.

According to Table 5, the distribution of well depth and economic infeasibility can be fitted. According to 


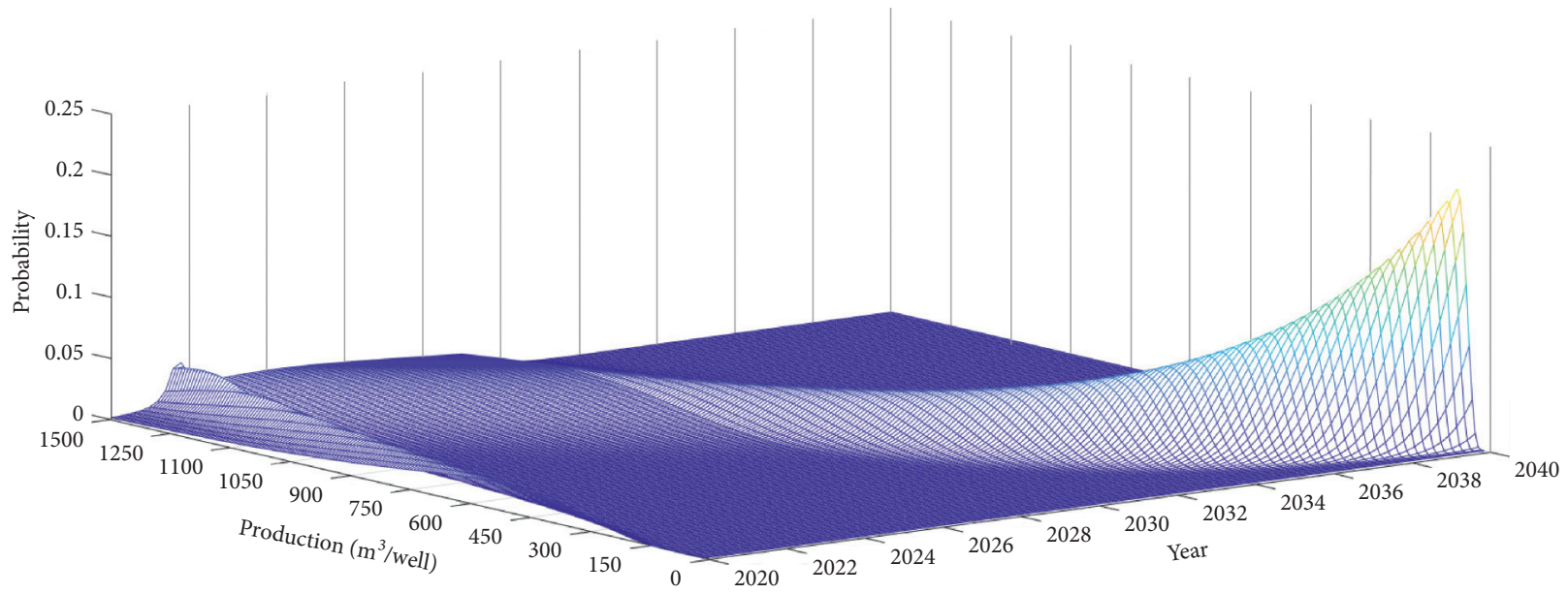

FIGURe 3: Probability density for the single-well gas output curve of deep CBM in Block Ji 4\&10.

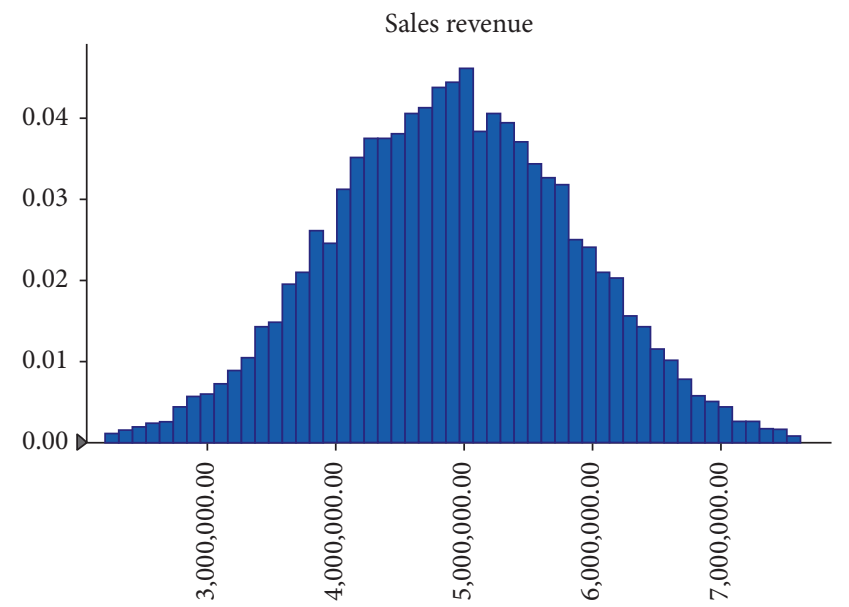

FIGURE 4: Probability distribution of future sales income (present value).

Anderson-Darling test results, the distribution is most likely logarithmic normal distribution. The fitting result of distribution is shown in Figure 8.

According to calculation, the mean of the distribution is 1,331 , with the standard deviation of 683 , and the values of $\mathrm{P} 10, \mathrm{P} 50$, and $\mathrm{P} 90$ of the distribution are $2,203.20 \mathrm{~m}$, $1,186.04 \mathrm{~m}$, and $631.35 \mathrm{~m}$, respectively, which means that for Block Ji 4\&10, when the drilling depth is higher than $2,203.20 \mathrm{~m}$, the probability of economic infeasibility is higher than $90 \%$.

5.3.3. Calculation Results of Well Spacing Limit. Similar to the example of the limit of well depth, the economic limit boundary can also be calculated according to the economic infeasibility probabilities at different well spacings. Since the calculation process is similar to the abovementioned, the fitting picture is omitted. In Table 4, the designed well densities are, respectively, $6.25,8.16$, and $11.11 \mathrm{wells} / \mathrm{km}^{2}$, corresponding to well spacings of $400 \mathrm{~m} \times 400 \mathrm{~m}$, $350 \mathrm{~m} \times 350 \mathrm{~m}$, and $300 \mathrm{~m} \times 300 \mathrm{~m}$, respectively. After fitting, the gas reservoir coefficient $z$ has a quadratic

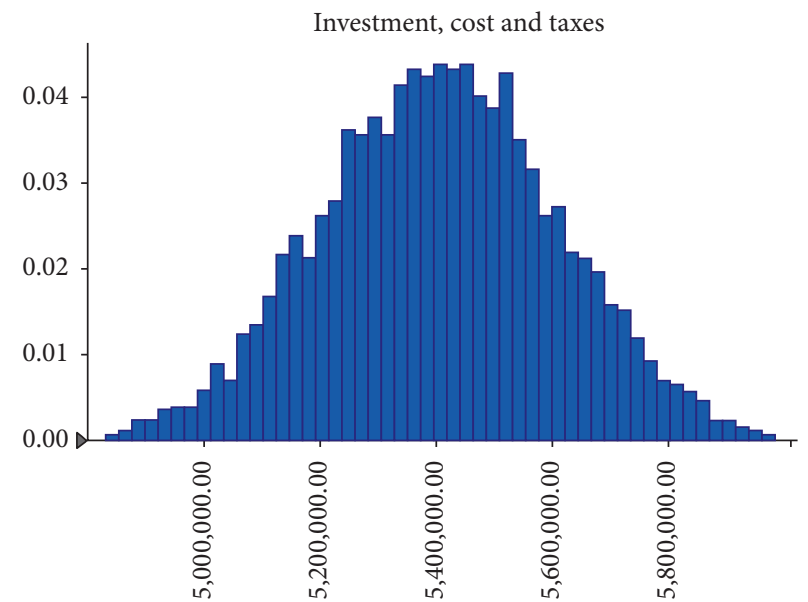

FIgURE 5: Probability distribution of future total expenditure (present value).

relationship with the well control area, and the relationship between well spacing and recovery ratio in Block Ji $4 \& 10$ is shown in the following formula:

$$
R_{r}=82 \% \times e^{-342.2(a \times b)^{3}+94.35(a \times b)^{3}-9.36(a \times b)} .
$$

Similarly, the economic infeasibility probabilities at different well spacings are calculated according to Table 4 and formulas (13)-(15) and (22). The economic infeasibility probabilities at different well densities are shown in Table 6.

After fitting, the data in Table 6 do not conform to any known distribution, so the boundaries need to be calculated by interpolation. As can be seen from Table 6, when the well density is higher than 11.11 wells $/ \mathrm{km}^{2}$, the well spacing is $300 \mathrm{~m} \times 300 \mathrm{~m}$, the recovery ratio is $59.11 \%$, and the probability of economic infeasibility is higher than $92.3 \%$, and then the well spacing is considered as the minimum limit. According to trial calculation with interpolation, when the well density is lower than 4.54 wells $/ \mathrm{km}^{2}$, the well spacing is $469 \mathrm{~m} \times 469 \mathrm{~m}$, the recovery ratio is $26.33 \%$, and the economic infeasibility probability is higher than $89.7 \%$, and then the well spacing is considered as the maximum limit. 


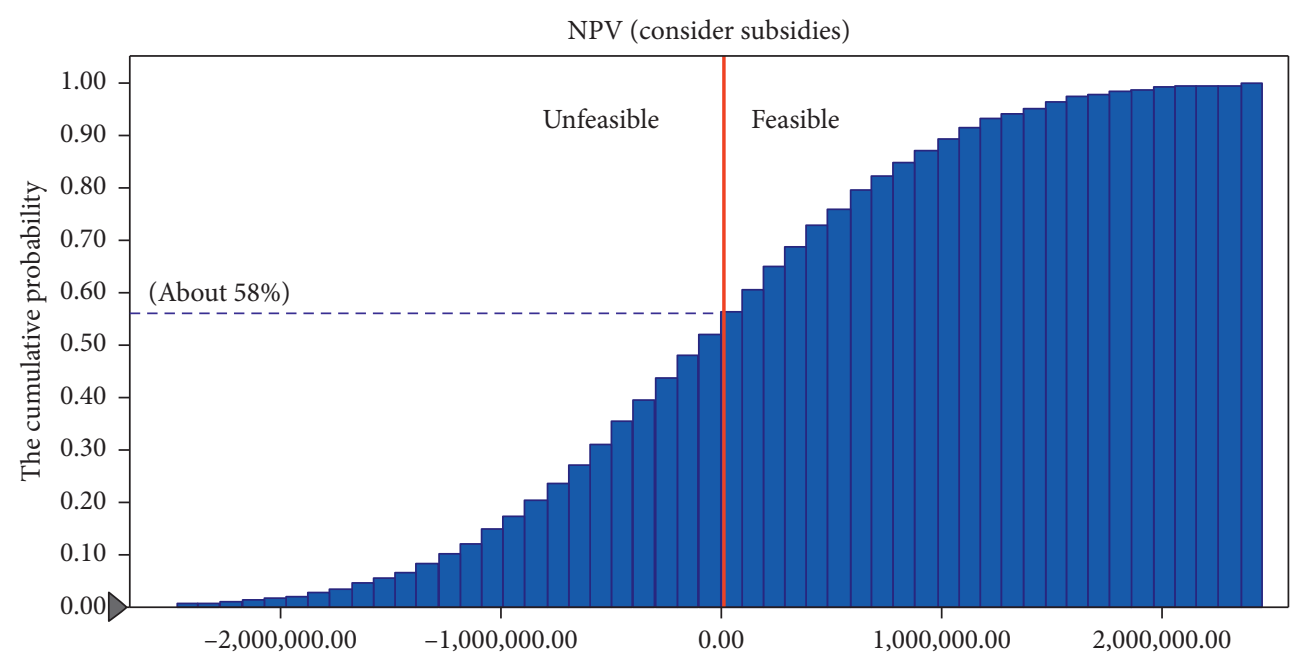

Figure 6: Cumulative probability of the future net present value (NPV) in Block Ji 4\&10.

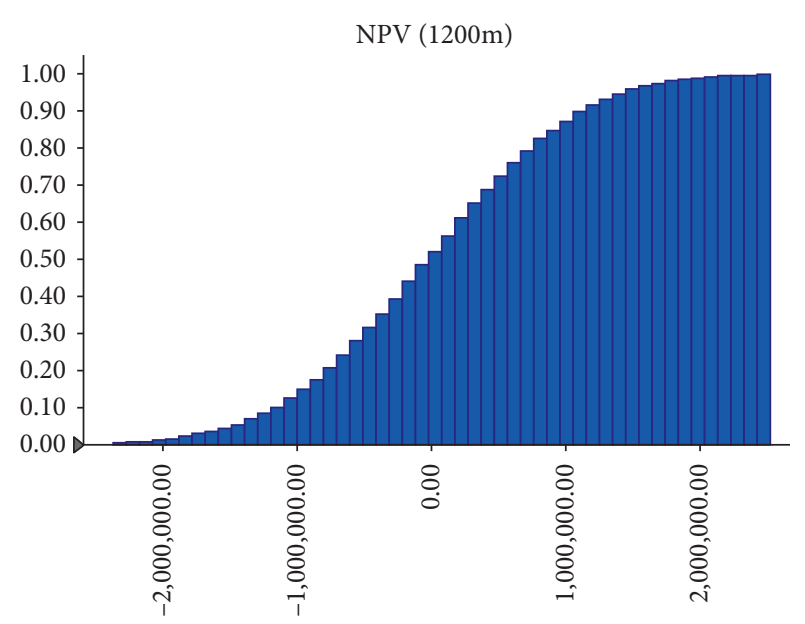

Figure 7: Cumulative probability of NPV at the well depth of $1,200 \mathrm{~m}$.

TABle 5: Probability of economic infeasibility at different well depths.

\begin{tabular}{lcc}
\hline Depth $(\mathrm{m})$ & Drilling cost $\left(10^{4} ¥\right)$ & $P(\mathrm{NPV}<0)(\%)$ \\
\hline 1200 & 143.59 & 51.8 \\
1250 & 151.98 & 53.1 \\
1300 & 160.38 & 57.6 \\
1350 & 168.76 & 60.7 \\
1400 & 177.16 & 64.1 \\
\hline
\end{tabular}

5.3.4. Calculation Results of Gas Recovery Rate Limit. Through fitting formula (16), the relationship between gas recovery rate and recovery ratio in stable production period of Block Ji $4 \& 10$ is shown in the following formula:

$$
q_{D}=8.897 \% \times\left(1-R_{r}\right)^{2}+2.35 \% .
$$

With the maximum expected life of the pipeline network taken as 30 years and the year when the sales revenue cannot afford the operating costs taken as the time to stop production, the economic infeasibility probabilities of different gas recovery rates are also calculated. According to Table 4 and formulas (16), (17), and (23), the economic infeasibility probabilities at different gas recovery rates are shown in Table 7.

According to Table 7 , the gas recovery rate and the economic infeasibility probability are distributed in an inverted triangle, with the economic infeasibility probability decreasing first and then increasing with the increase of the gas recovery rate. According to Table 7 , when the gas recovery rate is higher than $4.3 \%$, the recovery ratio is $52.0 \%$, and the probability of economic infeasibility is higher than $89.4 \%$, and such rate is considered as the maximum limit of gas recovery rate. After trial calculation with interpolation, when the gas recovery rate is lower than $2.1 \%$, the recovery ratio is $63 \%$ and the economic infeasibility probability is higher than $91.7 \%$ due to the limitation of well pattern life, and such rate is considered as the minimum limit of gas recovery rate.

\section{Conclusion}

The development of China's unconventional natural gas is facing three new situations, pricing reform, subsidy competition, and reduced production capacity growth, which may cause the development of unconventional natural gas to be on the edge of economic feasibility. Therefore, more accurate requirements have been put forward for methods to define economic limits. Based on the prediction of the prices and subsidies of three unconventional natural gases and the impact of well depth, well spacing, and gas recovery rate on relevant investment costs and recovery ratio and by obtaining the break-even point with probability density functions, the following conclusions have been drawn:

(1) The future prices of unconventional natural gas in China are determined by the market. The subsidy is affected by competition and increment, and the growth rate of production will be reduced. The prediction results (Figure 2) show that, without considering technological progress, the total amount 


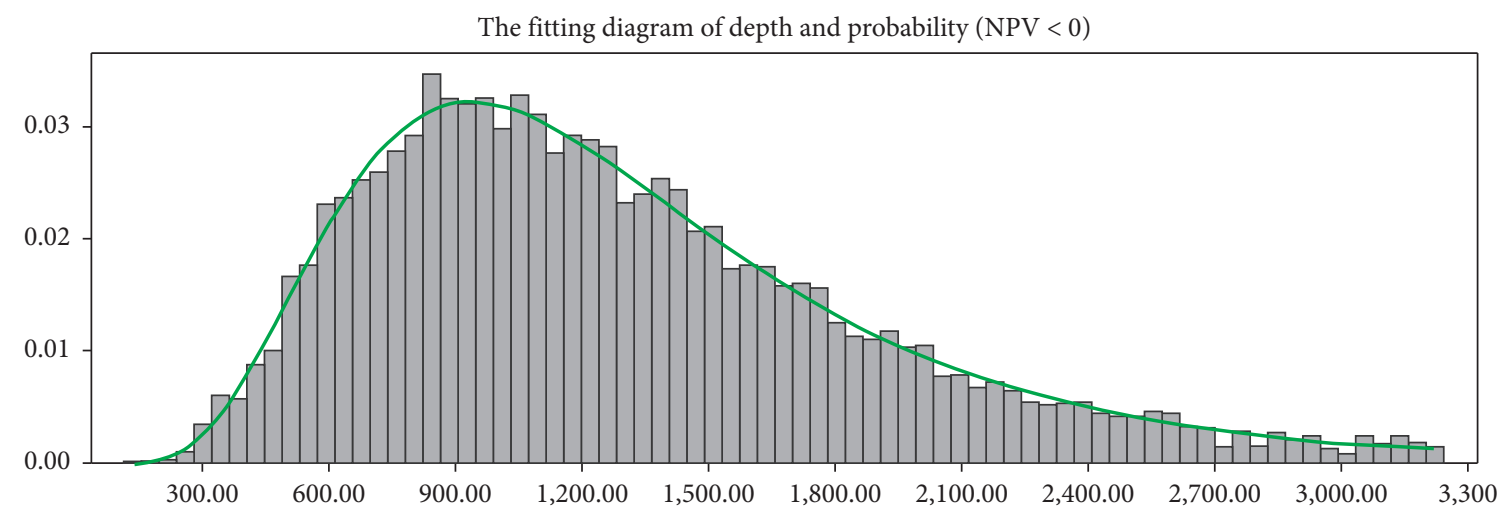

FIGURE 8: Distribution fitting of drilling depth and economic infeasibility probability (increment).

TABLE 6: Economic infeasibility probabilities at different well spacings.

\begin{tabular}{lccc}
\hline Density $\left(\right.$ well $\left./ \mathrm{km}^{2}\right)$ & Well spacing $(\mathrm{m} \times \mathrm{m})$ & Recovery $(\%)$ & $P(\mathrm{NPV}<0)(\%)$ \\
\hline 6.25 & $400 \times 400$ & 50.56 & 31.2 \\
7.14 & $400 \times 350$ & 54.98 & 39.7 \\
8.16 & $350 \times 350$ & 57.24 & 56.7 \\
9.52 & $350 \times 300$ & 58.45 & 82.7 \\
11.11 & $300 \times 300$ & 59.11 & 92.3 \\
\hline
\end{tabular}

TABLE 7: Economic infeasibility probabilities at different gas recovery rates.

\begin{tabular}{lccc}
\hline Recovery rate (\%) & Year of stable production & Recovery $(\%)$ & $P(\mathrm{NPV}<0)(\%)$ \\
\hline 3.1 & 11.1 & 72.7 & 52.4 \\
3.3 & 9.5 & 72.0 & 48.2 \\
3.5 & 8.6 & 67.9 & 43.7 \\
3.7 & 7.7 & 63.6 & 47.3 \\
3.9 & 6.6 & 60.1 & 54.6 \\
4.1 & 5.9 & 56.2 & 63.8 \\
4.3 & 5.2 & 52.0 & 89.4 \\
\hline
\end{tabular}

of unconventional natural gas in China will peak at about 120 billion $\mathrm{m}^{3}$ in the future, with shale gas taking the leading position and CBM gradually declining. With the total amount of subsidy unchanged, the amount of subsidy will be reduced from RMB 0.3 to RMB 0.06 per cubic meter in the future.

(2) The designed discounted cashflow probability density model can use fuzzy data to solve the economically feasible probability in the form of probability distribution function. Based on this model, through break-even analysis with the subsection function of drilling cost to well depth, the modified Cher Card Geoff empirical formula of recovery ratio to well spacing, as well as the fitting formula of gas recovery rate and stable production time, the economic feasibility probabilities at different values of well depth, well spacing, and well density can be obtained, and the economic limits at various confidence levels can be obtained through fitting distribution and trial calculation with interpolation.

(3) Deep CBM Block Ji 4\&10 was taken as an example, whose economic feasibility probability was calculated to be $42 \%$. After calculation, when the well depth exceeds $2,203.20 \mathrm{~m}$, the well spacing is less than $300 \mathrm{~m} \times 300 \mathrm{~m}$ or more than $469 \mathrm{~m} \times 469 \mathrm{~m}$ and the gas recovery rate is less than $2.1 \%$ or more than $4.3 \%$, the economic infeasibility probability will be as high as $90 \%$. This shows that there are great risks in the development of this block and indicates that more attention should be paid to the economic feasibility of unconventional oil and gas development under new situations.

\section{Data Availability}

All data used to support the findings of this study are available from the corresponding author upon request.

\section{Conflicts of Interest}

The authors declare that they have no conflicts of interest.

\section{References}

[1] S. Tao, S. D. Chen, and Z. J. Pan, "Current status, challenges, and policy suggestions for coalbed methane industry development in China: a review," Energy Science \& Engineering, vol. 7, pp. 1-16, 2019. 
[2] J. J. Liu and X. He, Economic Evaluation on Well Space Density in Oilfield, Orient Acad Forum, Marrickville, Australia, 2008.

[3] S. Gao, H. Liu, L. Ye, Z. Wen, W. Zhu, and C. Zhang, "A new method for well pattern density optimization and recovery factor evaluation of tight sandstone gas reservoirs," Natural Gas Industry, vol. 39, pp. 58-65, 2019.

[4] S. Zhang and Y. Huang, "Net present value Method: a new method to calculate economy limit well density," Geological Science and Techology Information, vol. 23, pp. 78-80, 2004.

[5] C. Han, M. Luo, D. H. Zhang, and B. H. Wu, "Iterative learning method for drilling depth optimization in peck deephole drilling," Journal of Manufacturing Science and Engineering, vol. 140, no. 12, 2018.

[6] J. Shen, Y. Qin, X. Fu, G. Chen, and R. Chen, "Properties of deep coalbed methane reservoir-forming conditions and critical depth discussion," Natural Gas Geoscience, vol. 25, no. 9, pp. 1470-1476, 2014.

[7] S. Chen, D. Tang, S. Tao, J. Zhao, Y. Li, and W. Liu, "Discussion about "critical depth" of deep coalbed methane in Zhengzhuang area, Qinshui Basin,” Journal of China Coal Society, vol. 41, no. 12, pp. 3069-3075, 2016.

[8] Y.-S. Yuan, Z.-J. Jin, Y. Zhou, J.-X. Liu, S.-J. Li, and Q.-Y. Liu, "Burial depth interval of the shale brittle-ductile transition zone and its implications in shale gas exploration and production," Petroleum Science, vol. 14, no. 4, pp. 637-647, 2017.

[9] L. Xia and D. Luo, "A method for calculating economic critical depth of shale gas resources in China via break-even analysis," Journal of Natural Gas Science and Engineering, vol. 21, pp. 1091-1098, 2014.

[10] R. Sheng and X. Li, "Influences of gas recovery rate and aquifer size on production of sandstone water-drive gas reservoirs," Petroleum Exploration and Development, vol. 32, pp. 94-97, 2005.

[11] H. Wen, Y. Chen, and Y. Feng, "New method for productivity analysis of gas/water breakthrough well in pressure-sensitive gas reservoir," Petroleum Geology \& Oilfield Development in Daqing, vol. 30, pp. 111-114, 2011.

[12] Y. Zeng, L. He, J. Liao, D. Yang, and B. Li, "Productivity analyses of non-darcy permeable flow in stress-sensitivity and low-permeability gas reservoirs with vertical fractures," Special Oil \& Gas Reservoirs, vol. 19, 2012.

[13] C. Guo, F. Li, H. Liu et al., "Analysis of quantitative relationship between gas offtake and plateau duration of natural gas reservoir," Acta Petrolei Sinica, vol. 30, no. 6, pp. 908-911, 2009.

[14] M. N. Fonseca, E. d. O. Pamplona, V. E. d. M. Valerio, G. Aquila, L. C. S. Rocha, and P. Rotela Junior, "Oil price volatility: a real option valuation approach in an African oil field," Journal of Petroleum Science and Engineering, vol. 150, pp. 297-304, 2017.

[15] Y. Q. Zhou and L. Yan, "Comparing two models for evaluating an oilfield development project: mean-reversion with jumps, geometric brownian motion," Sustainable Development of Natural Resources, pp. 1568-1572, Trans Tech Publications Ltd, Stafa-Zurich, Switzerland, 2013.

[16] P. Berg and S. Korte, "Higher-order Hubbert models for world oil production," Petroleum Science and Technology, vol. 26, no. 2, pp. 217-230, 2008.

[17] Y. Zhou, F. Zhou, and L. Feng, "A new model for predicting oil and gas production," Petroleum Geology \& Oilfield Development in Daqing, vol. 37, pp. 76-80, 2018.

[18] M. Ebrahimi and N. Cheshme Ghasabani, "Forecasting OPEC crude oil production using a variant multicyclic Hubbert
Model," Journal of Petroleum Science and Engineering, vol. 133, pp. 818-823, 2015.

[19] T. Xu, F. Lianyong, and Z. Lin, "Prediction and analysis of world oil supply pattern based on generalized Weng's model," Resources Science, vol. 31, pp. 238-242, 2009.

[20] E. D. Attanasi and R. R. Charpentier, "Comparison of two probability distributions used to model sizes of undiscovered oil and gas accumulations: does the tail wag the assessment?" Mathematical Geology, vol. 34, no. 6, pp. 767-777, 2002.

[21] D. G. Quirk and R. Ruthrauff, "Analysis of reserves discovered in petroleum exploration," Journal of Petroleum Geology, vol. 29, no. 2, pp. 125-146, 2006.

[22] S. Tao, Z. Pan, S. Tang, and S. Chen, "Current status and geological conditions for the applicability of CBM drilling technologies in China: a review," International Journal of Coal Geology, vol. 202, pp. 95-108, 2019.

[23] J. Huang, "A new method of economic limit well pattern density calculation in oilfields," Petroleum Geology and Recovery Efficiency, vol. 20, p. 53, 2013.

[24] C. Yu, H. Li, M. Zhao, and C. Luo, "Calculation methods of rational infill well number in water drive field," Lithologic Reservoirs, vol. 23, pp. 111-113, 2011.

[25] X. Xie, X. Qin, and Z. chen, "One calculation method to demonstrate the well spacing density of CBM well," Science Technology and Engineering, vol. 14, pp. 3271-3274, 2011.

[26] S. Tao, S. Chen, D. Tang, X. Zhao, H. Xu, and S. Li, "Material composition, pore structure and adsorption capacity of lowrank coals around the first coalification jump: a case of eastern Junggar Basin, China,” Fuel, vol. 211, pp. 804-815, 2018.

[27] S. Tao, Z. Pan, S. Chen, and S. Tang, "Coal seam porosity and fracture heterogeneity of marcolithotypes in the Fanzhuang Block, southern Qinshui Basin, China," Journal of Natural Gas Science and Engineering, vol. 66, pp. 148-158, 2019. 